\title{
THE OSTEOGENIC EFFECT OF BONE TRANSPLANTS IN RABBITS
}

\author{
H. Bohr, H. O. Ravn and H. Werner, Copenhagen, Denmark
}

From The Orthopaedic Hospital, Copenhagen

One of the main problems of bone transplantation has been the question of survival of cells from autografts and their capacity for bone formation. Puranen (1966) showed that fresh autografts of bone have a more intense uptake of tetracycline than autografts which have been exposed for one hour to air or kept for three hours in saline, and he suggested that the greater osteogenic power of fresh autografts was due to survival of bone-producing cells.

This observation has been further studied in the present investigation, where bone production at different periods after transplantation was observed by labelling with tetracycline compounds.

\section{TECHNIQUE AND MATERIALS}

White rabbits three to four months old and weighing 1.5 kilograms were operated upon under Nembutal anaesthesia. The skin was incised along the iliac crest and the iliac bone was exposed by retraction of the muscles including most of the periosteum. A cylindrical bone graft consisting of outer and inner cortices and intermediate cancellous bone was taken with a hand drill. In some cases the bone grafts were replaced immediately; in others they were kept in saline or exposed to air for one hour before replacement. In similar experiments fresh autografts were transplanted to muscle tissue beneath the fascia on the back of the animals and in these cases processed cancellous heterogenous bone (" Kiel bone," Maatz and Bauermeister 1957) was inserted in the defect of the iliac bone. Finally, in some animals Kiel bone was embedded in muscular tissue. A prophylactic dose of penicillin $(50,000$ units) was given to each animal after operation.

TABLE I

MATERIAL

\begin{tabular}{|c|c|c|c|}
\hline $\begin{array}{c}\text { Type of } \\
\text { graft }\end{array}$ & $\begin{array}{c}\text { Transplantation } \\
\text { method }\end{array}$ & $\begin{array}{c}\text { Number of } \\
\text { grafts }\end{array}$ & $\begin{array}{c}\text { Number of } \\
\text { sections }\end{array}$ \\
\hline Auto & Immediately replaced & 15 & 44 \\
\hline Auto & One hour in saline & 13 & 38 \\
\hline Auto & One hour air exposure & 14 & 42 \\
\hline Auto & Muscle & 17 & 43 \\
\hline Hetero & Kiel bone to bone & 12 & 35 \\
\hline Hetero & Kiel bone to muscle & 23 & 55 \\
\hline
\end{tabular}

Five days after the operation the animals received an injection of Terramycin (oxytetracycline) 20 milligrams per kilogram body weight intramuscularly, and five days later an injection of Ledermycin (dimethyl-chlor-tetracycline) 25 milligrams per kilogram body weight intramuscularly or intravenously. The animals were killed by an overdose of Nembutal two weeks after operation. 
The experiments comprise forty-one animals which were operated on bilaterally. No accidental death occurred after the operations and there was no infection. At necropsy the muscles overlying the transplants showed some fibrotic changes and mostly adhered to the bone. A haemorrhagic cyst appeared in a few cases at the transplantation site, but did not seem to interfere with consolidation between the graft and the host bone. The iliac bone was removed in toto and after fixation in 10 per cent formalin and dehydration in increasing concentrations of ethyl alcohol it was embedded in methylmethacrylate. Transverse sections were made of the entire specimen and sections including the grafts were cut to $50 \mu$ thickness. In a few cases such sections were stained with haematoxylin and eosin, after further grinding to $20 \mu$ and treatment with Moliifex, an organic solvent.* The grafts transplanted to muscle tissue were divided: one half was embedded in methylmethacrylate, and the other half was decalcified and treated as an ordinary histological specimen and stained with haematoxylin and eosin. The number of different grafts and sections are shown in Table I, where it is seen that two or three sections were available from each graft. Examination for fluorescence in ultraviolet light was made with the use of Reichert filters G.G. 9/1 millimetres+O.G. 0/1, 5 millimetres, through which the yellowish-green fluorescence of Terramycin could be clearly distinguished from the bright yellow fluorescence of Ledermycin. Microradiographic investigations were made using a Machlett 50 A.E.G. x-ray tube with Wolfram anode and generated at 12 kilovolts and $12 \mathrm{~mA}$. Exposures were made on Kodak Spectroscopic films $649 \mathrm{O}$ during 10 minutes at a focus distance of 15 centimetres.

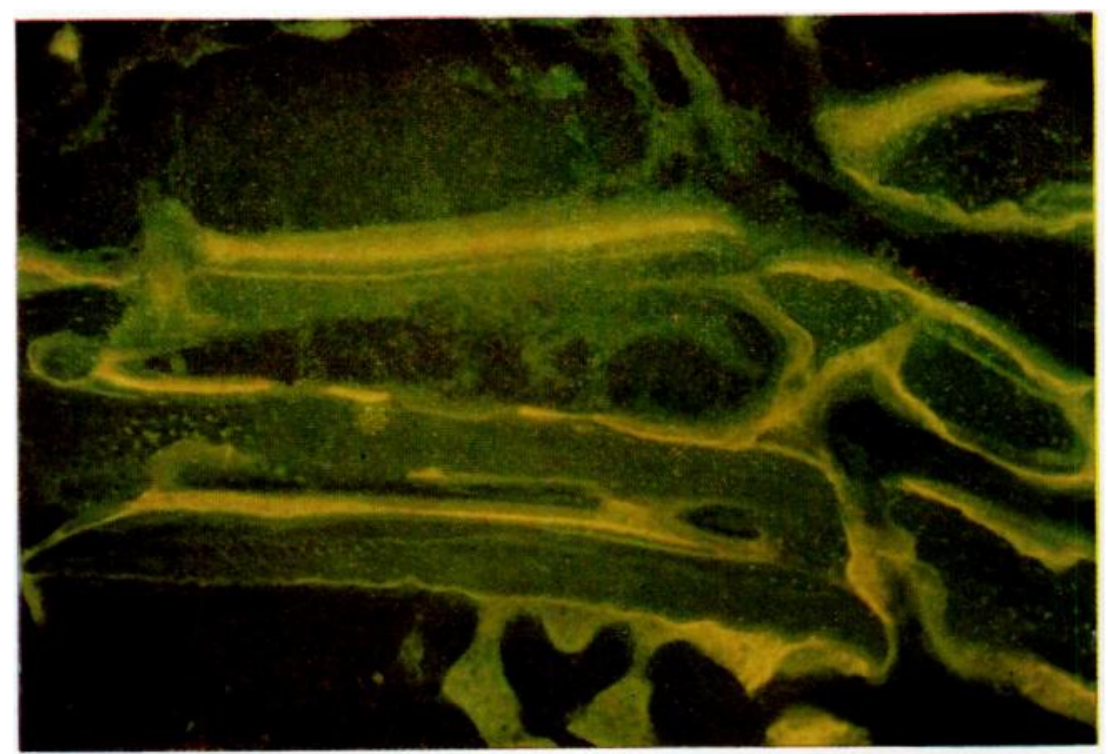

FiG. 1

Fresh autograft fifteen days after transplantation to bone. Green line from labelling with Terramycin five days after transplantation. Yellow line from labelling with Ledermycin ten days after transplantation. Distinct double labelling is seen. (Fluorescence microscopy, $\times 16$.)

\section{RESULTS}

Bone formation within the grafts and as callus was estimated in relation to tetracycline labelling. When fluorescence both from Terramycin and Ledermycin was seen on the same bone surfaces as distinct lines separated by a layer of unlabelled bone, it was described as double labelling for the purpose of this investigation (Fig. 1). The extent of double labelling

$$
\text { * From British Drug Houses Ltd. }
$$

VOL. 50 B, No. 4, NOVEMBER 1968 
in sections from the different grafts is shown in Table II, where extensive double labelling on most surfaces is indicated as ++ , while distinct double labelling on a few surfaces only is indicated + , and doubtful or no double labelling is indicated as 0 . It is seen that 55 per cent

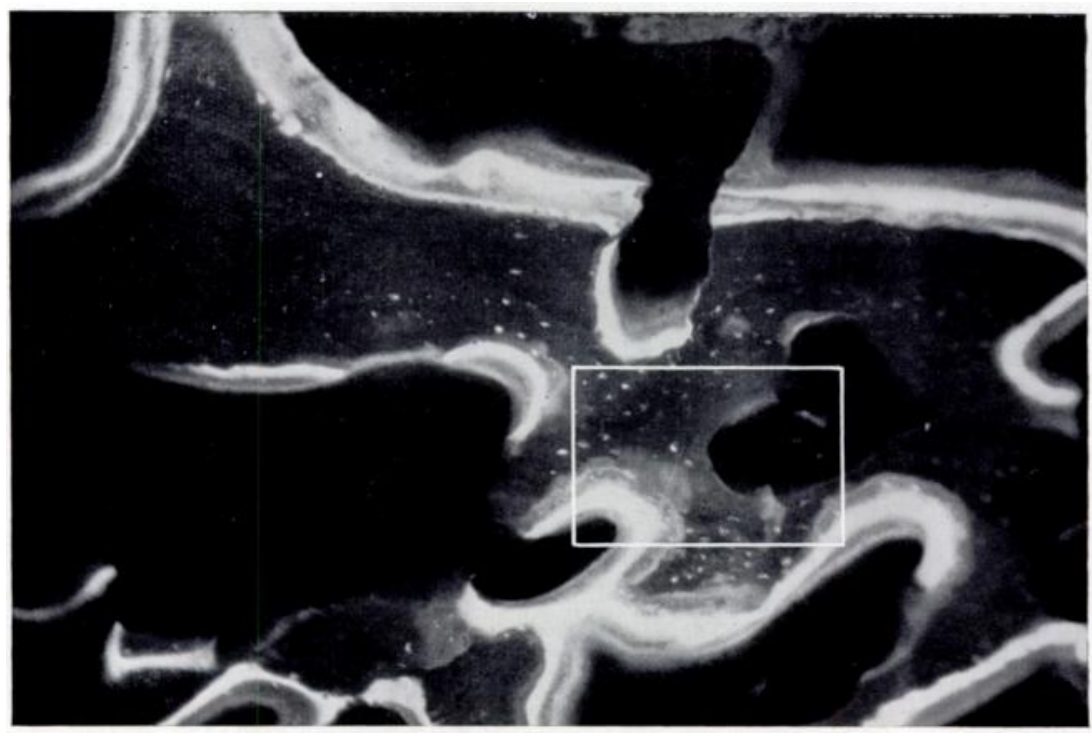

Fig. 2

Fresh autograft fifteen days after transplantation to bone. Double labelling on bone surfaces is seen. (Fluorescence microscopy, $\times 25$.)

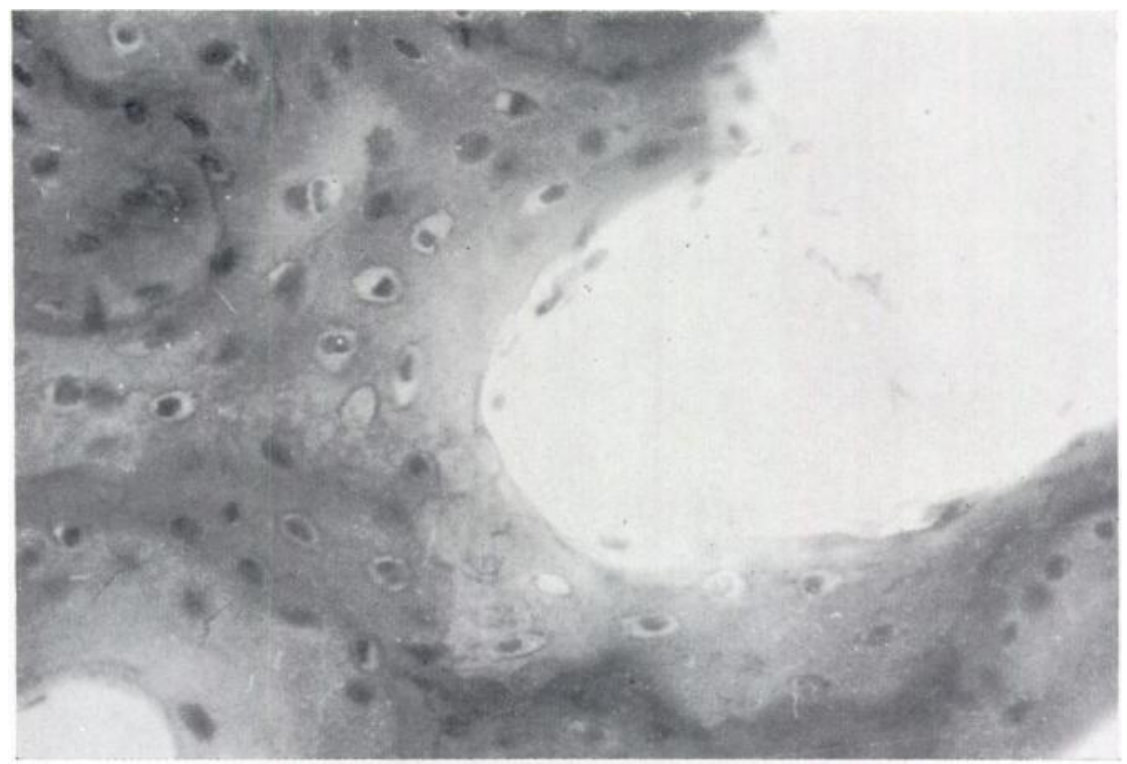

FIG. 3

Framed area of Figure 2. Viable osteocytes are seen in double labelled area. (Haematoxylin and eosin, $\times 100$.)

of the sections obtained from fresh autografts transplanted to bone showed either $(++)$ or $(+)$ double labelling. In the autografts kept in saline for one hour before replacement 42 per cent of the sections showed extensive or distinct double labelling, while in autografts exposed to 


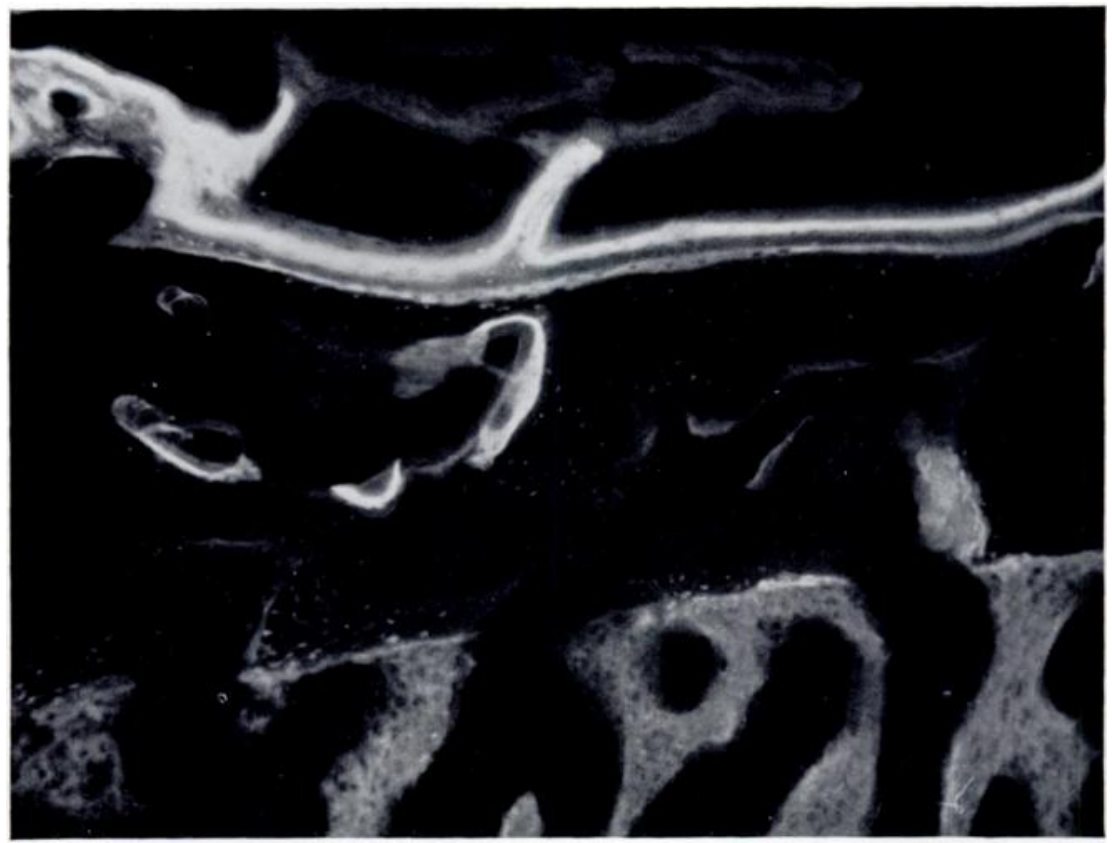

Fig. 4

Fresh autograft fifteen days after transplantation to bone. Double labelling on the upper surface and diffusely labelled callus on the lower surface. (Fluorescence microscopy, $\times 25$.)

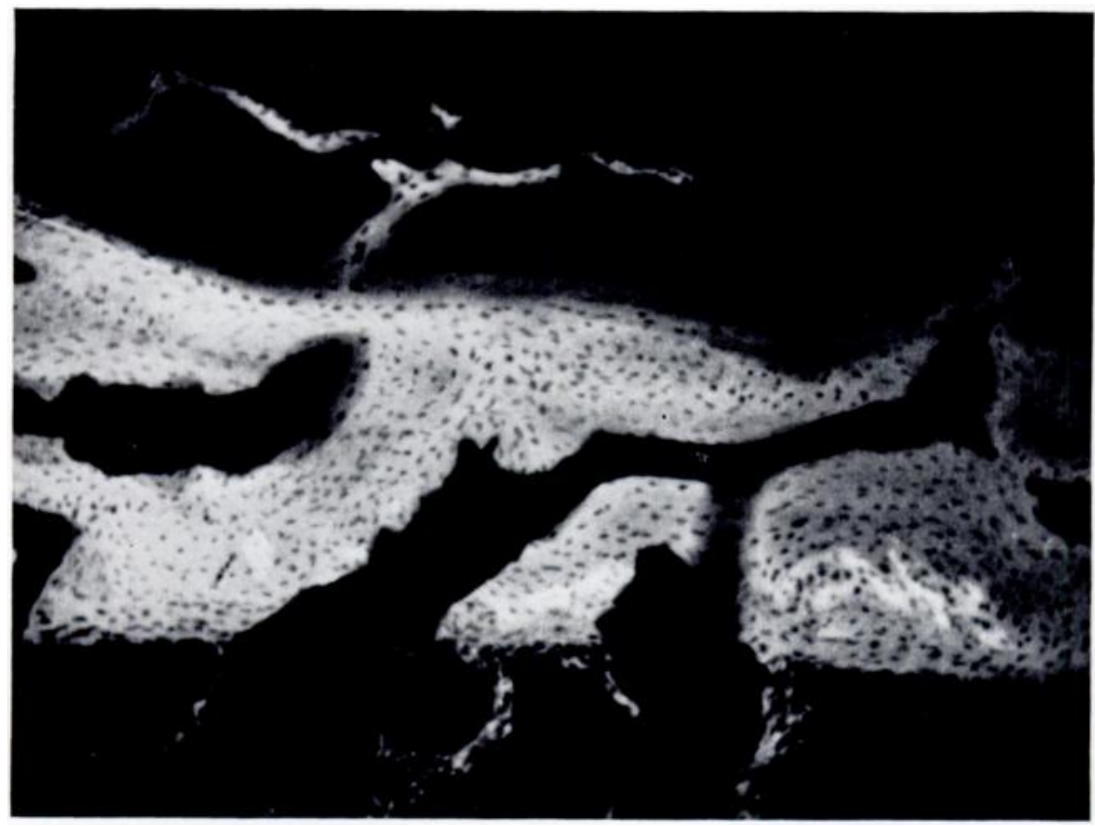

FIG. 5

Same section as in Figure 4. Secondary bone corresponding to double labelling. (Microradiography, $\times 25$.) 
air for one hour before replacement double labelling was seen in only 14 per cent of the sections. No double labelling was observed in fresh autografts transplanted to muscle tissue, and this was also the case in Kiel bone inserted either in bone or muscle tissue.

Five animals had injections of Ledermycin on the day before transplantations of fresh autografts to bone and injections of Terramycin four days after transplantation. In these autografts extensive or distinct double labelling was present in fourteen of the twenty-nine sections.

TABLE II

Double Labelling of Transplants

\begin{tabular}{|c|c|c|c|c|}
\hline \multirow{2}{*}{$\begin{array}{c}\text { Type of } \\
\text { graft }\end{array}$} & \multirow{2}{*}{\begin{tabular}{|} 
Transplantation \\
site
\end{tabular}} & \multicolumn{3}{|c|}{$\begin{array}{l}\text { Degree of double labelling } \\
\text { (per cent of sections) }\end{array}$} \\
\hline & & ++ & + & 0 \\
\hline Auto fresh & Bone & 16 & 39 & 45 \\
\hline Auto saline & Bone & 13 & 29 & 58 \\
\hline Auto air & Bone & 0 & 14 & 86 \\
\hline Auto fresh & Muscle & $\mathbf{0}$ & 0 & 100 \\
\hline Kiel bone & Bone & 0 & 0 & 100 \\
\hline Kiel bone & Muscle & 0 & 0 & 100 \\
\hline
\end{tabular}

TABLE III

Callus Formation in Contact with the Graft

Labelled callus present at the tenth day after transplantation. Unlabelled callus developed from the tenth to the fifteenth day

\begin{tabular}{|c|c|c|c|c|c|c|c|}
\hline \multirow{2}{*}{$\begin{array}{c}\text { Type of } \\
\text { graft }\end{array}$} & \multirow{2}{*}{$\begin{array}{c}\text { Transplantation } \\
\text { site }\end{array}$} & \multicolumn{3}{|c|}{$\begin{array}{l}\text { Degree of labelled callus } \\
\text { (per cent of sections) }\end{array}$} & \multicolumn{3}{|c|}{$\begin{array}{l}\text { Degree of unlabelled callus } \\
\text { (per cent of sections) }\end{array}$} \\
\hline & & ++ & + & 0 & ++ & + & 0 \\
\hline Auto fresh & Bone & 2 & 78 & 20 & 14 & 75 & 11 \\
\hline Auto saline & Bone & $\mathbf{0}$ & 74 & 26 & 8 & 87 & 5 \\
\hline Auto air & Bone & 0 & 62 & 38 & 2 & 81 & 17 \\
\hline Auto fresh & Muscle & 0 & 84 & 16 & 16 & 75 & 9 \\
\hline Kiel bone & Bone & 0 & 14 & 86 & 0 & 80 & 20 \\
\hline Kiel bone & Muscle & 0 & 0 & 100 & 0 & 0 & 100 \\
\hline
\end{tabular}

In the stained sections viable osteocytes were seen in double labelled areas of the grafts as shown in Figures 2 and 3. Microradiographic investigations showed that the bone formed between the two tetracycline lines is of a mature, secondary type in contrast to the callus formation appearing as primary bone, where the lacunae are greater and more irregularly arranged and where the uptake of tetracycline is more diffuse, as seen in Figures 4 and 5.

Besides bone formation in the graft demonstrated by double labelling, the amount of callus formation in close contact with the grafts was estimated as shown in Table III. It is seen that callus, which was labelled with Ledermycin ten days after transplantation, was present in extensive $(++)$ or distinct $(+)$ amounts in 80 per cent of the sections from fresh autografts transplanted to bone, in 74 per cent of the sections from autografts kept in saline and in 62 per cent of the sections from autografts exposed to air for one hour. The autografts 
transplanted to muscle showed extensive or distinct callus formation at this stage in 84 per cent of the sections. In grafts of Kiel bone inserted to bone, labelled callus was seen in only 14 per cent. The amount of unlabelled callus produced between the tenth and the fifteenth day after transplantation showed little difference between the various autografts irrespective of treatment and transplantation site. In grafts of Kiel bone inserted to bone, unlabelled callus was present in 80 per cent of the sections. No callus formation was seen in grafts of Kiel bone inserted to muscle tissue. The histological investigation of the autografts transplanted to muscle tissue showed that few if any of the osteocytes survived, and that in most cases callus formation was present as seen in Figure 6.

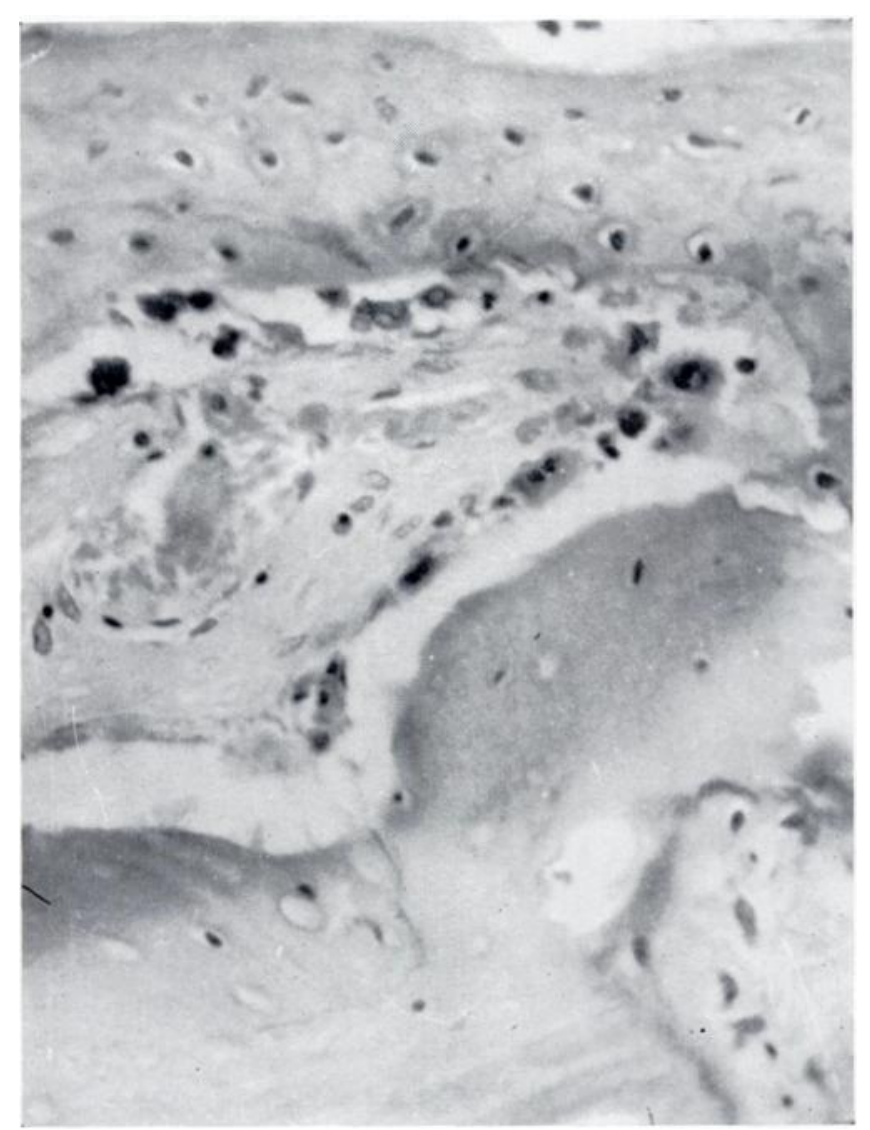

FIG. 6

Fresh autograft fifteen days after transplantation to muscle tissue. New bone formation as callus is seen on the surface of the necrotic graft. (Haematoxylin and eosin, $\times 100$.)

\section{DISCUSSION AND CONCLUSIONS}

Since the observation that tetracyclines are taken up in living bone and retained at the site of new bone formation, where it can be demonstrated by fluorescence in ultraviolet light (Milch, Rall and Tobie 1957, 1958), this phenomenon has been widely used in the study of bone formation. Although dead bone may also be labelled with tetracyclines in vitro (Deleu and Bohr 1964; Steendijk 1964; Tapp, Kovács and Carroll 1965), it has been demonstrated that tetracyclines are preferably taken up where bone is being deposited (Harris, Jackson and Jowsey 1962). Different ways of applying the tetracyclines have been described. Some authors use a single administration of tetracycline, while others have employed continuous

VOL. 50 B, NO. 4, NOVEMBER 1968 
administration over several days or repeated administration with one or more intervals (Frost 1960; Frost, Villanueva and Roth 1960; Amprino and Marotti 1964; Sissons and Lee 1964; Sluys Veer, Smeenk and Heul 1964; Puranen 1966). Without entering into a more thorough discussion of the various methods we would emphasise that the demonstration of unlabelled bone between the lines of tetracycline following repeated labelling offers a direct proof that new bone formation has taken place, and by giving compounds of tetracycline with different fluorescent colours (Harris 1960) the time of bone formation has teen determined.

From the present investigation it follows that new bone is deposited on the surface of fresh autografts between the fifth and the tenth day after transplantation to bone, and that storage in saline for one hour before replacement has little adverse effect, whereas exposure to air for one hour seems to reduce bone formation markedly at this early stage. In fresh autografts new bone formation has been demonstrated even within the first four days after transplantation to bone, when penetration of vessels from the host should not be expected (Deleu and Trueta 1965). These results show that osteogenic cells from autografts may survive and continue bone formation after transplantation under favourable conditions. This is in accordance with results obtained from isotransplantations of bone using either tritium-labelled thymidin (Ray and Sabet 1963) or sex chromatine tracing (Arora and Laskin 1964).

The presence of viable osteocytes in the double labelled areas (Fig. 3) as well as the demonstration of secondary bone between the tetracycline lines (Fig. 5) indicates that the surviving osteogenic cells are derived from the bone structure.

The fact that double labelling was not seen in fresh autografts transplanted to muscle tissue is in accordance with the histological investigations showing that few, if any, of the osteocytes of the grafts survive under these conditions (Fig. 6). Callus formation in contact with these grafts at an early stage may be due to surviving osteoblasts, but the possibility of transformation of more primitive cells, originating either from the graft or from the host, into osteogenic cells should also be considered in this connection (Bertelsen 1944; Danis 1957; Urist, Wallace and Adams 1965; Burwell 1966).

In transplantations to bone it is difficult to distinguish whether callus is developing from the graft or from the host tissue. As callus formation during the first ten days after transplantation is significantly greater in autografts than in grafts of Kiel bone, this is an indication of the osteogenic effect of the autografts. At a later stage, when the difference between callus formation in cases of autografts and grafts of Kiel tone diminishes, the spontaneous regeneration of the host bone seems to be the main source of new bone formation.

\section{SUMMARY}

1. Transplantations of autografts and of Kiel bone to the iliac bone and to muscle tissue were performed in rabbits. Through labelling with two tetracycline compounds which have different fluorescent colours in ultraviolet light, bone formation between the labelling periods could be followed.

2. It was shown that bone formation between the fifth and the tenth day after transplantation to bone took place in about 50 per cent of the fresh autografts. Storage of the transplants in saline for one hour before replacement had little adverse effect, whereas exposure to air for one hour seemed to reduce the osteogenic effect of the grafts. Bone formation was not observed in grafts of Kiel bone during this period.

3. The fact that new bone formation in fresh autografts could be demonstrated even during the first four days after transplantation to bone indicates that osteogenic cells from the fresh autografts continue their activity under favourable conditions. This is supported by microradiographic and histological evidence.

4. The amount of callus which developed in close contact with the grafts during the first ten days after transplantation to bone was more pronounced both in fresh autografts and in 
autografts kept in saline than in autografts exposed to air for one hour. Callus developing at a later stage showed no significant difference between the various grafts, including those of Kiel bone.

5. In fresh autografts transplanted to muscle tissue callus formation could be demonstrated in most cases by the tenth day, indicating either survival of osteoblasts or the transformation of more primitive cells from the graft or from the host bone into osteogenic cells. No bone formation was observed when Kiel bone was embedded in muscle tissue.

We wish to express our gratitude to Miss $\mathrm{M}$. Bertran for valuable technical assistance, and thank the Cyanamid Overseas Corporation, Copenhagen, for the Ledermycin kindly put at our disposal.

\section{REFERENCES}

Amprino, R., and MARotri, G. (1964): A Topographic, Quantitative Study of Bone Formation and Reconstruction. Bone and Tooth, Proceedings of the First European Symposium, pp. 21-33. Edited by Blackwell. London: Pergamon Press.

Arora, B. K., and LaSkin, D. M. (1964): Sex Chromatin as a Cellular Label of Osteogenesis by Bone Grafts. Journal of Bone and Joint Surgery, 46-A, 1269.

Bertelsen, A. (1944): Experimental Investigations into Post-foetal Osteogenesis. Acta Orthopaedica Scandinavica, 15, 139.

Burwell, R. G. (1966): Studies in the Transplantation of Bone. VIII. Treated Composite Homograftautografts of Cancellous Bone: an Analysis of Inductive Mechanisms in Bone Transplantation. Journal of Bone and Joint Surgery, 48-B, 532.

Danis, A. (1957): Etude de l'ossification dans les greffes de moelle osseuse, pp. 65-66. Les Editions Acta Medica Belgica, Bruxelles.

Deleu, J., and Bohr, H. (1964): Uptake of Tetracycline by Human Bone in vitro. Nature, 204, 1103.

Deleu, J., and Trueta, J. (1965): Vascularisation of Bone Grafts in the Anterior Chamber of the Eye. Journal of Bone and Joint Surgery, 47-B, 319.

Frost, H. M. (1960): Lamellar Osteoid Mineralized pr. Day in Man. Henry Ford Hospital Medical Bulletin, $8,2,267$.

Frost, H. M., Villanueva, A. R., and Roth, H. (1960): Measurement of Bone Formation in a 57-year-old Man by Means of Tetracyclines. Henry Ford Hospital Medical Bulletin, 8, 2, 239.

Harris, W. H. (1960): A Microscopic Method of Determining Bone Growth. Nature, 188, 1038.

Harris, W. H., Jackson, R. H., and Jowsey, J. (1962): The IN VIVO Distribution of Tetracyclines in Canine Bone. Journal of Bone and Joint Surgery, 44-A, 1308.

MaAtZ, R., and Bauermeister, A. (1957): A Method of Bone Maceration. Results in Animal Experiments. Journal of Bone and Joint Surgery, 39-A, 153.

Milch, R. A., RALL, D. P., and TOBIE, J. E. (1957): Bone Localisation of Tetracyclines. Journal of the National Cancer Institute, 19, 87.

Milch, R. A., RALL, D. P., and ToBie, J. E. (1958): Fluorescence of Tetracycline Antibiotics in Bone. Journal of Bone and Joint Surgery, 40-A, 897.

Puranen, J. (1966): Reorganization of Fresh and Preserved Bone Transplants. Acta Orthopaedica Scandinavica, Supplementum 92.

RAY, R. D., and SABET, T. Y. (1963): Bone Grafts: Cellular Survival Versus Induction. Journal of Bone and Joint Surgery, 45-A, 337.

Sissons, H. A., and Lee, W. R. (1964): Tetracycline Studies in Bone Turnover. Bome and Tooth. Proceedings of the First European Symposium, pp. 65-69. Edited by Blackwell. London: Pergamon Press.

StefnDIJK, R. (1964): Studies on the Mechanism of the Fixation of the Tetracyclines to Bone. Acta Anatomica, S6, 368.

Tapp, E., Kovács, K., and Caroll., R. (1965): Tetracycline Staining of Tissues IN VITRO. Stain Technology, 40, 199.

Urist, M. R., Wallace, T. H., and Adams, T. (1965): The Function of Fibrocartilaginous Fracture Callus. Journal of Bone and Joint Surgery, 47-B, 304.

Van der Sluys Veer, J., Smeenk, D., and Van der Heul, R. O. (1964): Tetracycline Labelling of Bone in Hyperparathyroidism. Bone and Tooth. Proceedings of the First European Symposium, pp. 85-91. Edited by Blackwell. London: Pergamon Press. 